\title{
Pregnancy with chronic myeloid leukemia: case report and literature review
}

\author{
Tanzeem Sabina Chowdhury*, Israt Jerin, T. A. Chowdhury
}

Department of Obstetrics and Gynecology, BIRDEM General Hospital and Ibrahim Medical College, 122, Kazi Nazrul Islam Avenue, Shahbag, Dhaka, Bangladesh

Received: 31 August 2019

Accepted: 30 September 2019

\section{*Correspondence:}

Dr. Tanzeem Sabina Chowdhury,

E-mail: tanzeemsc@gmail.com

Copyright: ( $)$ the author(s), publisher and licensee Medip Academy. This is an open-access article distributed under the terms of the Creative Commons Attribution Non-Commercial License, which permits unrestricted non-commercial use, distribution, and reproduction in any medium, provided the original work is properly cited.

\section{ABSTRACT}

Chronic myeloid leukemia (CML) is a rare condition during reproductive age. Still, women may present with preexisting or newly diagnosed CML during pregnancy. The management of chronic myeloid leukemia during pregnancy requires balancing the well-being of the mother with that of fetus. Tyrosine Kinase inhibitors are considered the most effective drug against CML but they are still not considered safe during pregnancy and breast feeding. So, there is a need for management of CML with alternate drugs during pregnancy. Here we report a case of a 26-year-old lady who was diagnosed with chronic myelogenous leukemia (CML) at 20 weeks of gestation and had an atypical chromosome translocation $\mathrm{t}$ (9:22). She was managed jointly by obstetrician and haemato-oncologist for the remainder of her pregnancy and eventually she delivered a healthy baby at term.

Keywords: Chronic myeloid leukemia, Hydroxyurea, Interferon- $\alpha$, Leukemia, Teratogenicity, Tyrosine kinase inhibitor

\section{INTRODUCTION}

Chronic myeloid leukemia (CML) is a myelo proliferative disorder with clonal expansion of transformed primitive hematopoietic progenitor cells. This genetic anomaly arises from an exchange of genetic material between chromosome 9 and 22, which results in the fusion of the breakpoint cluster region (BCR) and the Abelson cellular proto-oncogene (ABL) gene. The BCR$\mathrm{ABL}$ fusion protein has tyrosine kinase activity that activates a number of intracellular proteins and responsible for this disease. CML constitutes $15 \%$ of adult leukemia. ${ }^{1}$ Its incidence varies from 0.6 to $2.0 /$ 100,000 persons, increasing with age. The median age at diagnosis of CML is 64 years and approximately $17 \%$ of cases occur in the age group of 20-44 years. ${ }^{2}$ The male is more affected than female. ${ }^{3}$
Simultaneous presentation of pregnancy and CML is an uncommon event. The management of CML during pregnancy is a challenging task both for the patient and the physician because of the potential adverse effects of chemotherapy on the mother and teratogenicity in the fetus. We hereby report the successful management of pregnancy in a woman who was diagnosed to have CML in the second trimester of pregnancy.

\section{CASE REPORT}

A 26-year-old woman in her 20th week of gestation was having continuous low-grade fever for 1 month. She went to local physician and her investigations found that she had elevated white blood cell count. The initial blood picture showed- WBC 72,000 cells $/ \mathrm{mm}^{3}$, hemoglobin $11.2 \mathrm{gm} / \mathrm{dl}$, hematocrit $36 \%$ and platelets $562,000 / \mathrm{mm}^{3}$. 
MCV was 95fl. Differential count revealed $80 \%$ polymorphonuclear leukocytes, $8 \%$ lymphocytes, $1 \%$ monocytes, $1 \%$ eosinophils and $1 \%$ basophils. Other laboratory studies, including electrolytes and liver function tests were normal. She was then referred to a hematologist and BCR-ABL gene rearrangement test (PCR qualitative) was done which came out positive. Type of translocation was major. Bone marrow examination was done where features were consistent with chronic myeloid leukemia in chronic phase. Ultrasonogram of whole abdomen was done which revealed no organomegaly, lymphadenopathy or ascites. Detailed anomaly scan revealed no gross fetal abnormality, which was done at $20^{\text {th }}$ week of gestation. As there was no abnormality on anomaly scan, a joint decision was taken by the patient, her physician and obstetrician to continue the pregnancy. She took tablet hydroxyurea (400 mg) 12 hourly every day until her delivery. Her pregnancy proceeded uneventfully.

Her white cell count came down to $35,000 / \mathrm{mm}^{3}$ and platelet count was $2,57.000 / \mathrm{mm}^{3}$ at term. At her 38 weeks of pregnancy on $2^{\text {nd }}$ November, 2018, she got admitted in BIRDEM hospital and delivered a healthy female baby of $2.6 \mathrm{~kg}$ by lower uterine caesarean section. As it was her $4^{\text {th }}$ pregnancy and she had three healthy children before, bilateral tubectomy was done during her cesarean section. At her $4^{\text {th }}$ post-operative day, she was discharged from the hospital with standard post-natal and immunization advice and referred to her haematooncologist for further evaluation and management of her condition.

As per his advice, she started imatinib mesylate (400 mg) daily and was advised not to breast feed her baby. She was given tablet bromocriptine $(2.5 \mathrm{mg})$ for 14 days to suppress breast milk. She was followed up at 6 days and 6 weeks post-partum which revealed that she had no obstetric complications. She was advised to be under constant supervision of her physician.

\section{DISCUSSION}

Chronic myeloid leukemia is a rare condition especially during pregnancy $(1: 100,000){ }^{4}$ Diagnosis is usually made in the second or third trimester of pregnancy as the early symptoms are often nonspecific and imitates the symptoms of early pregnancy. Pregnancy does not affect chronic myeloid leukemia but there are the risks of leukostasis and placental insufficiency with consequent low birth weight, premature delivery and increased mortality. ${ }^{5}$

Cytotoxic treatment for CML during pregnancy poses a very difficult therapeutic dilemma, with variable immediate and late effects on the fetus. The risks are concentrated in the first trimester and depend on the chemotherapeutic agents used. Discovery of tyrosine kinase inhibitors (TKIs) has led to marked improvement in survival of chronic myelogenous leukemia (CML) patients changing the once fatal disease into a truly chronic condition. Since the first administration of imatinib (the first of the TKIs) to patients with CML in June 1998, it is estimated that there have now been 250,000 patient years of exposure to the drug (mostly in patients with CML). ${ }^{6}$ Dasatinib, nilotinib and bosutinib are the newer TKIs which are approved by FDA as firstline therapy for CML. TKIs not only target BCR-ABL tyrosine kinase but also c-kit, platelet derived growth factors receptors $\alpha$ and $\beta$ (PDGFR- $\alpha / \beta)$, ARG and cFMS. $^{7}$ These proteins are known to have functions that may be important in gonadal development, implantation and fetal development. So, this raises considerable safety concern for the use of TKIs in pregnancy. Currently there are few cases reports showing successful pregnancy outcome while the patient was on imatinib therapy but well-established data regarding fetal and neonatal exposure to TKIs in pregnant women with CML are lacking. Thus, TKIs are better avoided during pregnancy as first line treatment of chronic myeloid leukemia. Most of the available literature also suggests that imitanib and its active metabolite are secreted in human milk to variable extent. So, breast feeding is also contraindicated during imatinib therapy.

Both hydroxyurea and interferon have been used successfully during pregnancy without any teratogenicity or fetal malformation.

Interferon-alpha (IFN- $\alpha$ ) was the non-transplant treatment of choice for most patients with CML before the advent of TKI (imatinib). ${ }^{8}$ IFN- $\alpha$ acts by (i) selective toxicity against the leukemic clone, (ii) enhancement of 'immune' regulation and (iii) modulation of bone marrow microenvironmental regulation of hematopoiesis. ${ }^{9}$ Due to its high molecular weight $(19 \mathrm{kDa})$, treatment with IFN- $\alpha$ adequately controls the leukemic cell mass in the majority of newly diagnosed patients with CML. IFN- $\alpha$ does not cross the placental barrier to a great extent. ${ }^{10}$ Due to the lack of concrete evidence of any teratogenic effect of interferon, it is considered a safe drug to be administered throughout pregnancy. But no data is available regarding the safety of IFN- $\alpha$ during breastfeeding and it is unknown if any component of the drug is excreted in breast milk. IFN therapy is associated with significant toxicities, mostly constitutional, neuropsychiatric, hematologic and hepatic effects which may have a major impact on the patient's quality of life.

Hydroxyuria is another alternative drug which can be used during pregnancy. It is a cytotoxic drug that inhibits DNA synthesis by decreasing the production of deoxyribonucleotides by inhibition of the enzyme ribonucleotide reductase. ${ }^{9}$ Although up to 90 percent of CML patients treated with hydroxyurea may experience clinical and hematological remission, this treatment is not curative, and does not prolong overall survival. ${ }^{9}$ The risk for teratogenicity does not seem to be high, so can be used safely during pregnancy. Hydroxyurea is known to 
be excreted in breast milk and, therefore, should not be given to lactating women. ${ }^{11}$

Chronic myeloid leukemia can be managed conservatively during pregnancy by alternative method like leukapheresis. It is an attractive short-term alternative to chemotherapy for the pregnant patient especially during first trimester which causes a rapid lowering of high total leucocyte count. This procedure may provide an alternative treatment by chemotherapy to avoid the potential teratogenic and leukemogenic sideeffects of chemotherapy. But leukapheresis is costly and time consuming and currently not recommended as maintenance therapy for CML during pregnancy.

Allogenic stem cell transplantation remains an important treatment option for patients with CML, particularly younger individuals who have failed treatment with imatinib and have an HLA-identical donor. But due to the aggressiveness of this treatment and lack of concrete evidence, it is considered to be contra-indicated during pregnancy. ${ }^{12}$

No universal guidelines have been developed in management of pregnant women with chronic myeloid leukemia till now. Management of women with CML during pregnancy depends on the phase of the disease as well as duration of pregnancy. A woman with accelerated or blast phase CML should be started on chemotherapy immediately as it is a very grave situation. If the patient is in late trimester, early delivery should also be offered so that proper treatment can be started early. If she is diagnosed with accelerated phase during first trimester, termination of pregnancy should be considered after proper counseling with patient. ${ }^{12}$

For a chronic phase CML, those patients who are already on TKIs should be counseled about the risks and benefits of TKIs especially effects in fertility and can be offered sperm/oocyte cryopreservation before starting on TKIs. If a patient is already under TKI therapy and is pregnant, patients should be counseled on the risks and benefits of stopping TKIs. It is essential to consider the patient's wishes, disease status, current response to TKIs and availability of other alternative therapies before any decision regarding continuation or discontinuation of TKIs. TKIs can be stopped if the patient is in complete molecular remission (CMR) or complete cytogenetic response (CCyR) for at least 2 years. ${ }^{12}$ The patient should be followed-up regularly with blood counts and real time PCR during pregnancy. If the patient continues to be in CMR/CCyR, she could be followed-up until after delivery and started on TKIs. If there is loss of CMR then leukapheresis in the first trimester and IFN- $\alpha$, leukapheresis or both in the second and third trimesters can be considered. ${ }^{12}$ Women diagnosed first time during pregnancy can be treated with IFN- $\alpha$ or hydroxyurea with leukapheresis if needed.

\section{CONCLUSION}

Pregnancy in CML is an infrequent but serious problem. The increasing use of imatinib and other TKIs has revolutionized the management of CML but unfortunately data regarding teratogenicity and abortion rate in patients treated with these drugs is not sufficient for safe use during pregnancy. Based on the review of existing data, hydroxyurea, interferon $\alpha$ or the combination of both appears to be the safest treatment if CML is diagnosed during pregnancy. In woman who is a known case of CML before pregnancy, detailed counselling and meticulous disease monitoring may lead to many women wishing to conceive become pregnant with minimal effects to fetus or their disease status. Further research for newer and safer drugs is required in order to allow clinicians and patients to make informed decisions about this serious condition.

\section{Funding: No funding sources \\ Conflict of interest: None declared \\ Ethical approval: Not required}

\section{REFERENCES}

1. Weisberg E, Manley P, Mestan J, Cowan-Jacob S, Ray A, Griffin JD. AMN107 (nilotinib): a novel and selective inhibitor of BCR-ABL. $\mathrm{Br} \mathrm{J}$ Cancer. 2006;94(12):1765-9.

2. Howlader N, Noone AM, Krapcho M, Garshell J, Neyman N, Altekruse SF, et al. SEER cancer statistics review, 1975-2010, National Cancer Institute, 2012.

3. Kantarjian HM, Talpaz M. Definition of the accelerated phase of chronic myelogenous leukemia. J Clin Oncol. 1988;6:180-2.

4. Lichtman M, Liesveld J. Acute myelogenous leukemia. In: Beutler E, Lichtman M, Coller B, et al., editors. Williams Hematology. $6^{\text {th }}$ ed., volume 1047. New York, USA: McGraw-Hill; 2001:1074-1084.

5. Firas AS, Demeckova E, Mistrik M. Leukemia in pregnancy. Bratisl Lek Listy. 2008;109:364-6.

6. Pye SM, Cortes J, Ault P, Hatfield A, Kantarjian H, Pilot R, et al. The effects of imatinib on pregnancy outcome. Blood. 2008;111:5505-8.

7. Apperley J. Issues of imatinib and pregnancy outcome. J Natl Compr Canc Netw. 2009;7(10):1050-8.

8. Shapira T, Pereg D, Lishner M. How I treat acute and chronic leukemia in pregnancy? Blood Rev. 2008;22(5):247-59.

9. Dowding C, Gordon M, Guo AP, Maison D, Osterholz J, Siczkowski M, et al. Potential mechanisms of action of interferon- $\alpha$ in CML. Leuk Lymphoma. 1993;11(Suppl 1):185-91.

10. Roth MS, Foon KA. Alpha interferon in the treatment of hematologic malignancies. Am J Med. 1986;81(5):871-82. 
11. Sylvester RK, Lobell M, Teresi ME, Brundage D, Dubowy R. Excretion of hydroxyurea into milk. Cancer. 1987;60(9):2177-78.

12. Bhandari A, Rolen K, Shah BK. Management of chronic myelogenous leukemia in pregnancy. Anticancer Res. 2015;35:1-12.
Cite this article as: Chowdhury TS, Jerin I, Chowdhury TA. Pregnancy with chronic myeloid leukemia: case report and literature review. Int J Reprod Contracept Obstet Gynecol 2019;8:5046-9. 